\title{
Toenail Metal Concentration as Biomarker of Heavy Metal Exposure among Welders
}

\author{
Azian Hariri ${ }^{\# 1}$, Noraishah Mohamad Noor ${ }^{* 2}$, Nuur Azreen Paiman ${ }^{\# 1}$ \\ ${ }^{\#}$ Industrial and Indoor Environment Research Group (IIERG) Centre for Energy and Industrial Environment \\ Studies (CEIES), Faculty of Mechanical and Manufacturing Engineering, Universiti Tun Hussein Onn Malaysia, \\ 86400, Parit Raja, Batu Pahat, Johor, Malaysia \\ 1.azian@uthm.edu.my \\ ${ }^{3}$ nuurazreenpaiman@yahoo.com.my \\ * DRB-HICOM University of Automotive Malaysia \\ Kawasan Perindustrian Peramu Jaya, 26600 Pekan, Pahang, Malaysia \\ ${ }^{2}$ noraishah@dhu.edu.my
}

\begin{abstract}
This study examined the concentration of heavy metal accumulated in the toenail of welders and compared to the concentration of airborne heavy metal exposure in the breathing zone of the welders. Ten selected welders with adequate toenail growth were asked to clip all ten toenails for analysis. The heavy metal concentration in the welder's breathing zone was collected by using mixed cellulose ester filters by using low flow rate air sampling pump. Both toenails and airborne sample filters were analyzed for thirteen elements (Be, Al, Cr, Mn, Fe, Co, Ni, Cu, As, Mo, Ag, Cd and Pb) by using inductively coupled plasma mass spectrometry (ICP-MS). The results of the study show airborne concentration of chromium (maximum value of $0.788 \mathrm{mg} / \mathrm{m}^{3}$ ) and manganese (maximum value of $3.937 \mathrm{mg} / \mathrm{m}^{3}$ ) in the welder's breathing zone exceeded the permissible exposure limit of Malaysian regulation. In addition, there was a similar trend obtained from the average concentration of heavy metal in breathing zone air sampling and the average accumulation of heavy metal in welder's toenail. The results of the study suggest that toenail accumulation was a reliable biomarker for continuous heavy metal exposure among the investigated welders.
\end{abstract}

Keyword - Biomarker, Toenail, Welder, Welding Fumes

\section{INTRODUCTION}

The term "biomarker", refers to the indications of medical state observed from outside the patient, which can be measured accurately and reproducibly [1]. Welding fumes contain heavy metal constituent and the ability of biomarkers to detect the medical state of welders is promising. It is highlighted that comparison of several biomarker such as blood, urine and nail may not help to determine the accuracy of individual marker since none of them can serve as a gold-standard marker [2]. Thus, the choice of appropriate biomarker is the reflection between exposure, biomarker and the exposure time period that the biomarker reflects [3]. Blood and urine may reflect exposure over a short and a recent period of time (hours to days), while nails and hair integrate exposure over a longer period of time and represent exposures over several months or longer [4].

In recent years, several researches had explored the possibility of toenail as biomarker of welding fumes exposure [3], [5]. Compare to hair, the toenail had the advantages of being sheltered from environmental contaminants and are less likely to have contaminants through hair shampooing, dyeing and bleaching [2].

Toenail clippings collected from all ten toes are likely to reflect exposure integrated over the previous 6 to 12 months, due to a growth rate of approximately $1.6 \mathrm{~mm} / \mathrm{month}$ and maximum average toenail length of 20 $\mathrm{mm}$ [3]. Given that nails are non-invasively and painlessly collected, and easy to store and transport, nail metal concentration should be intensively studied as a potential biomarker of internal dose for welding fume exposures [3].

Research on concentration of heavy metal in welder's toenail had been largely focused on manganese elements [3], [5]-[7]. Thus, this study focused on the concentration of overall 13 constituents of heavy metal detected in toenail and the airborne exposure in the welder's breathing zone. It is our main interest to investigate whether toenail could possibly become the biomarkers for welding exposure and represent overall 13 elements collected in the breathing zone of the welders.

\section{Methodology}

\section{A. Subjects of Study}

The study was conducted in a manufacturing company of armored vehicles. Ten welders working in air conditioned room were selected. The room equipped with centralized air conditioning system with the room area approximately $360 \mathrm{~m}^{2}$. The air conditioning system also equipped with an alarm system to give signal if the concentration of particulate matters/dust become too high. The welders work with gas metal arc welding 
(GMAW) with shielding gases of argon and carbon monoxide. The welding operation must be conducted in a controlled environment below $60 \%$ humidity to avoid hydrogen crack of the armored plate. There were four workstations equipped with portable fume captured system. However, the fume captured system is not practical since the welding work done on large parts and the welder has no fixed welding position. The welders are compulsory to wear personal protective equipment such as respirator, hand glove, safety boots and ear plug prior to entering the air conditioned welding room. Each welder normally works in average eight hours per day.

\section{B. Data Collected by Direct Reading Instruments}

Sampling by using direct reading instruments in the welding area was done to measure air velocity, temperature, relative humidity and particulate matters up to 10 micrometers in diameter sizes $\left(\mathrm{PM}_{10}\right)$ concentration. Sampling was done by using direct reading instruments (Dustrak Aerosol Monitor 8520 and TSI Velocicalc type 8386). One sampling point per workstation was chosen for direct reading data collection. Measurement of air velocity, temperature, relative humidity and respirable dust were measured for 15 minutes in each point with 1 minute interval. Samplings were done three time (morning (9.00 a.m), afternoon (11.30 a.m) and evening (3.00 p.m)).

\section{Breathing Zone Samples}

Welding fumes samples were conducted by locating the sampling head within the breathing zone of the welders. Personal sampling method was based on British Standard guidelines BS EN 689:1996 which stated at least one employee in ten of properly selected homogeneous group performing similar tasks must be sampled [8]. In this study, three welders which had the highest exposure to welding fumes and involved with high intensity welding works had been selected by the welder's supervisor to be sampled. The filters media (mixed cellulose ester $0.8 \mu \mathrm{m}$ pore sizes) was used with sampling pump set to $2 \mathrm{~L} / \mathrm{min}$ flow rate. In Malaysia, Under the Occupational Safety and Health Act 1994, Use and Standards of Exposure of Chemical Hazardous to Health regulation (USECHH) [9], chemical classified hazardous to health with its permissible emission limits (PEL) were listed and need to be comply by the employer. The collected samples were sent to the accredited laboratory for analysis. The analysis in certified laboratory was done based on American Society for Testing and Materials (ASTM) D7439-08 method by using inductively coupled plasma mass spectrometry (ICP-MS) (Agilent 7700) with microwave digestion of nitric acid and hydrochloric acid [10]. 13 elements concentration were analyzed (Be, $\mathrm{Al}, \mathrm{Cr}, \mathrm{Mn}, \mathrm{Fe}, \mathrm{Co}, \mathrm{Ni}, \mathrm{Cu}, \mathrm{As}, \mathrm{Mo}, \mathrm{Ag}, \mathrm{Cd}$ and $\mathrm{Pb}$ ). At least one field blanks were submitted together with batch of samples to the accredited laboratory for analysis. Duration of sampling was calculated and the concentrations of exposure were calculated in time weighted average 8 hours (TWA 8 ).

The equation for calculating the concentration of metal constituents in each sample is as follows;

$$
\rho_{m}=m / V
$$

where

$\rho_{m}=\quad$ calculated mass concentration of metal or metalloid in the air filter sample, in milligram per cubic meter, at ambient condition

$m=\quad$ calculated mass concentration of metal or metalloid in the air filter sample, in ppm

$V=\quad$ volume, in litres, of the collected samples

Calculation of the mass concentration of a metal constituent in ppm unit is as follows [10];

$$
m=\left\{\left[\left(\rho_{m, 1} \times V_{1} \times F\right)-\left(\rho_{m, 0} \times V_{0}\right)\right] / 1000\right\}
$$

where

$$
\begin{array}{lll}
m & = & \text { calculated mass concentration of metal or metalloid in the air filter sample, in ppm } \\
\rho_{m, 0} & = & \text { the mean concentration of metal and metalloid } \\
& & \text { in the blank solutions, in microgram per litre }
\end{array}
$$

The equation used to calculate the 8-hours TWA for personal sampling in the case studies is as follows;

$$
C(\text { TWA })=[C 1(T 1)+C 2(T 2)+\ldots+C n(T n)] / 8 \text { hour }
$$

where

$C(T W A)=$ the 8-hours time-weighted average, in milligram per cubic meter

$C=$ the concentration of a sample, in milligram per cubic meter

$T=$ the sampling time for that sample, in hours 


\section{Toenail samples}

Selected welders with adequate toenail growth were asked to clipped all ten toenails and placed in sealed plastic bag and label accordingly. Toenail samples were analyzed for 13 elements ( $\mathrm{Be}, \mathrm{Al}, \mathrm{Cr}, \mathrm{Mn}, \mathrm{Fe}$, $\mathrm{Co}, \mathrm{Ni}, \mathrm{Cu}, \mathrm{As}, \mathrm{Mo}, \mathrm{Ag}, \mathrm{Cd}$ and $\mathrm{Pb}$ ). Sample were analyze by accredited laboratory by using ICP-MS (Agilent 7700) adapted method based on AOAC999.10 9 method [11].

\section{III.RESULTS AND DISCUSSION}

The mean value of velocity, temperature, humidity and $\mathrm{PM}_{10}$ collected on all four workstations were as shown in Table 1 . The mean value of humidity were slightly higher on the morning session due to the outside weather condition on that that day. It was raining on the morning session of the sampling day. Temperature and air velocity inside the air-conditioned welding room were maintained at $22{ }^{\circ} \mathrm{C}$ and 0.06 to $0.11 \mathrm{~m} / \mathrm{s}$ respectively. The mean concentration of $\mathrm{PM}_{10}$ in noon increase two times higher compare to the concentration in the morning. Additionally the mean concentration of $\mathrm{PM}_{10}$ in the evening increased to an alarming values of four time higher compare to the concentration in morning. Apparently, there is an urgent need to reduce the concentration of $\mathrm{PM}_{10}$ through engineering control for adequate ventilation in the welding room.

Table 1: Direct reading instrument data

\begin{tabular}{llll}
\hline Parameters & $\begin{array}{l}\text { Morning } \\
\text { (mean) }\end{array}$ & $\begin{array}{l}\text { Afternoon } \\
\text { (mean) }\end{array}$ & $\begin{array}{l}\text { Evening } \\
\text { (mean) }\end{array}$ \\
\hline Velocity (m/s) & 0.10 & 0.11 & 0.06 \\
\hline Temperature $\left.\mathbf{(}^{\mathbf{0}} \mathbf{C}\right)$ & 22.80 & 22.90 & 22.60 \\
\hline Humidity $(\% \mathbf{r h})$ & 63.30 & 56.30 & 53.00 \\
\hline $\mathbf{P M}_{\mathbf{1 0}}\left(\mathbf{m g} / \mathbf{m}^{\mathbf{3}}\right)$ & 0.15 & 0.30 & 0.65 \\
\hline
\end{tabular}

Table 2 shows the concentration of heavy metal elements in the welder's breathing zone. Three samples were collected from the selected welders. The manganese level for these three welders exceeded up to 20 times higher than USECHH PEL value. In addition, chromium level of two of the investigated welders exceeded USECHH PEL value. Although two of the heavy metal element exceeded the USECHH PEL, the welders was wearing respirator during work. Thus, reduce the exposure of heavy metal towards welders. However, the use of respirators is the least satisfactory approach to exposure control. Respirators can only provide adequate protection if they are properly selected for the task, fitted to the wearer and are worn and maintained properly so that they continue to provide the protection required for the work situation It is suggested that exposure control through engineering such as air conditioning filtering and proper local exhaust ventilation installation must be considered for workplace safety and health improvement.

Table 2: Concentration of heavy metal elements in welder's breathing zone

\begin{tabular}{|c|c|c|c|c|}
\hline \multirow{2}{*}{ Elements } & \multicolumn{3}{|c|}{ Concentration $\left(\mathrm{mg} / \mathrm{m}^{3}\right)$} & \multirow{2}{*}{$\begin{array}{c}\text { USECHH } \\
\text { PEL }\end{array}$} \\
\hline & Welder 1 & Welder 2 & Welder 3 & \\
\hline Beryllium & 0.000 & 0.000 & 0.000 & $\begin{array}{c}0.002 \\
\text { C } 0.005\end{array}$ \\
\hline Aluminum & 0.125 & 0.193 & 0.128 & $\begin{array}{l}5.000 \\
\text { (resp.) }\end{array}$ \\
\hline Chromium & $\underline{0.697}$ & $\underline{0.788}$ & 0.456 & 0.500 \\
\hline Manganese & $\underline{1.802}$ & $\underline{3.937}$ & $\underline{2.049}$ & 0.200 \\
\hline Iron & 3.057 & 4.730 & 2.952 & 5.000 \\
\hline Cobalt & 0.002 & 0.002 & 0.001 & 0.100 \\
\hline Nickel & 0.257 & 0.206 & 0.150 & 1.500 \\
\hline Copper & 0.066 & 0.061 & 0.032 & 0.200 \\
\hline Arsenic & 0.002 & 0.001 & 0.001 & 0.010 \\
\hline Molybdenum & 0.015 & 0.011 & 0.009 & $\begin{array}{c}5.000 \\
\text { (soluble) }\end{array}$ \\
\hline Silver & 0.000 & 0.000 & 0.000 & 0.100 \\
\hline Cadmium & 0.000 & 0.001 & 0.000 & 0.500 \\
\hline Lead & 0.000 & 0.000 & 0.000 & 0.050 \\
\hline
\end{tabular}


Figure 1, Figure 2 and Figure 3 shows the graph plotted on minimum value, maximum value and average value for both toenail and breathing zone exposure respectively. Figure 1 and Figure 2 did not represent the same trend for both toenail and breathing zone exposure. However, Figure 3 of average value for toenail and breathing zone did show similar trend and in agreement with study done by R. Grashow et. al, F.I Abdulrahman et. al and K. Sriram et. al on the reliability of toenail metal concentration as biomarker for heavy metal exposure [3], [12], [13]. Thus, there is possibility to use toenail as biomarkers to assess exposure of welding fumes for continuous occupational exposure.

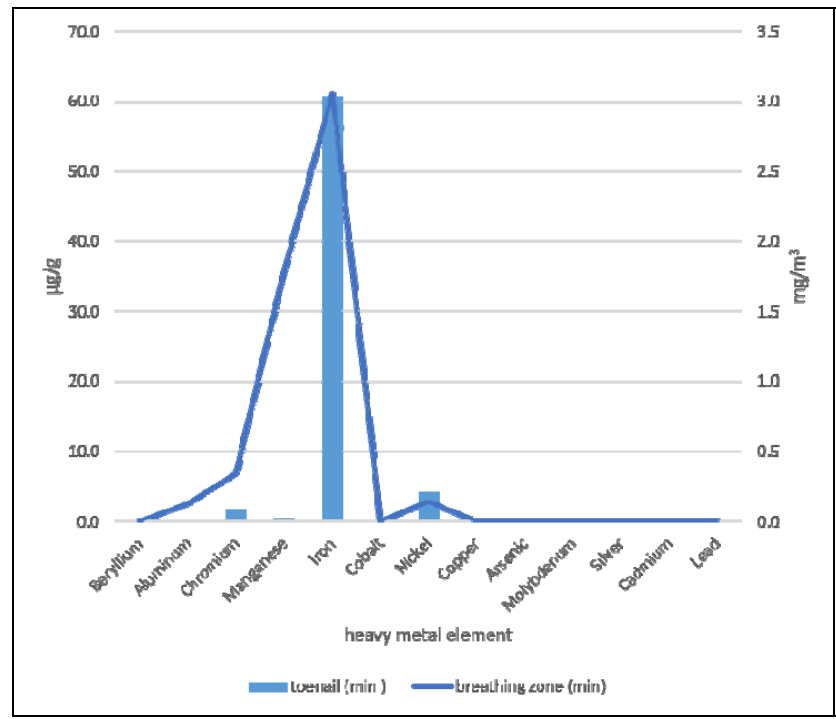

Figure 1: Minimum concentration of heavy metal in toenail and breathing zone of welders

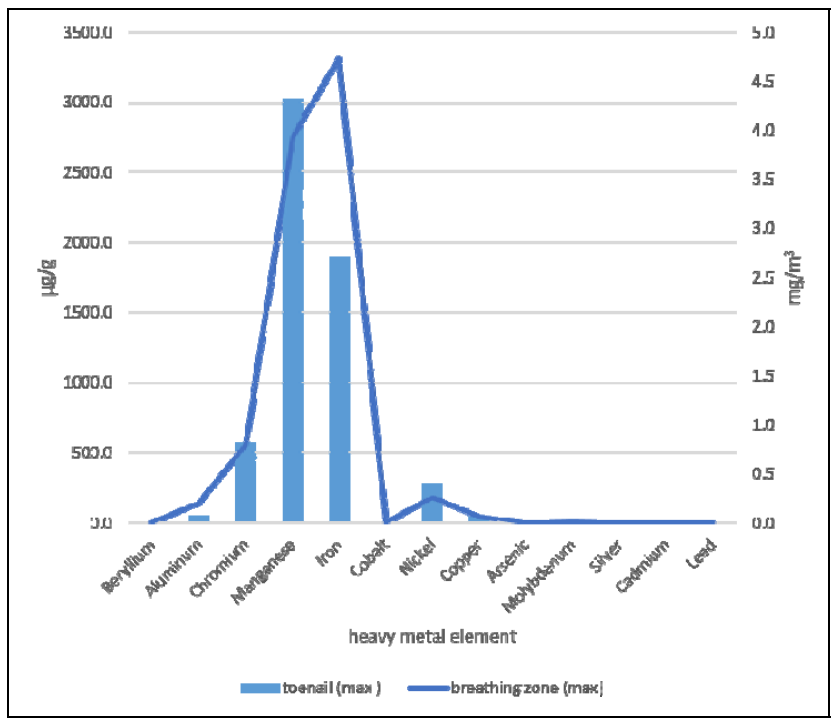

Figure 2: Maximum concentration of heavy metal in toenail and breathing zone of welders 


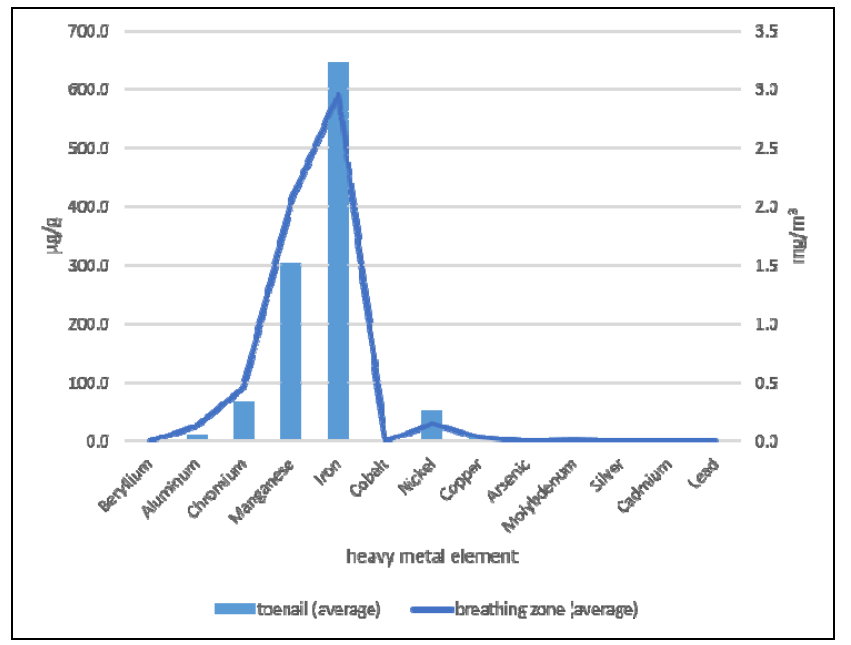

Figure 3: Average concentration of heavy metal in toenail and breathing zone of welders

\section{IV.CONCLUSION}

The concentration of $\mathrm{PM}_{10}$ in the welding room increased 4 times higher during evening compare to concentration in the morning. It is suggested that exposure control through filtering of air conditioning and proper installation of local exhaust ventilation system could help reduce the particulate exposure in the welding room.

Results of the study also shows airborne concentration of chromium and manganese in the welder's breathing zone exceeded the permissible exposure limit of Malaysian regulation. In addition, there was a similar trend obtained between the average concentration of heavy metal in breathing zone air sampling and the average accumulation of heavy metal in welder's toenail.

The results of the study suggest that the average toenail accumulation was a reliable biomarker for continuous heavy metal exposure among welders.

\section{ACKNOWLEDGMENT}

This work was supported in part by DRB Hicom University of Automotive Malaysia (DHUAM), Pekan Pahang and Universiti Tun Husseion Onn Malaysia, Batu Pahat, Johor under the Fundamental Research Grant Scheme (FRGS) vot 1539 .

\section{REFERENCES}

[1] K. Strimbu and J. Tavel, "NIH Public Access," Curr Opin HIV AIDS, vol. 5, no. 6, pp. 463-466, 2011.

[2] K. He, "Trace Elements in Nails as Biomarkers in Clinical Research," Eur J Clin Invest, vol. 29, no. 6, pp. 997-1003, 2012.

[3] R. Grashow, J. Zhang, S. C. Fang, M. G. Weisskopf, D. C. Christiani, and J. M. Cavallari, "Toenail metal concentration as a biomarker of occupational welding fume exposure.," Journal of occupational and environmental hygiene, no. January 2014, pp. 37-41, 2013.

[4] W. Laohaudomchok, X. Lin, R. F. Herrick, C. Shona, J. M. Cavallari, D. C. Christiani, and G. Marc, "NIH Public Access," vol. 53, no. 5, pp. 506-510, 2012.

[5] M. Ferreira, "Exposure of welders to manganese in welding fumes," MSc. thesis, Potchefstroom Campus of the North-West University., 2012.

[6] H. Hassani, F. Golbabaei, A. Ghahri, M. Hosseini, H. Shirkhanloo, B. Dinari, D. Eskandari, and M. Fallahi, “Occupational exposure to manganese-containing welding fumes and pulmonary function indices among natural gas transmission pipeline welders," Journal of Occupational Health, vol. 54, no. 4, pp. 316-322, 2012.

[7] B. Reiss, N. Seixas, P. I. Chris, S. Marissa, and C. Warner, "Hair as a biomarker for welder's exposure to manganese," 2012.

[8] British Standard Institute, "Workplace atmospheres guidance for the assessment of exposure by inhalation to chemical agents for comparison with limit values and measurement strategy: BS EN 689:1996," 1996.

[9] Malaysia, "Occupational Safety and Health (Use and Standards of Exposure to Chemical Hazardous to Health) (USECHH) : Regulation P.U. (A) 131,” 2000.

[10] American Society for Testing and Materials, "Determination of Elements in Airborne Particulate Matter by Inductively Coupled Plasma-Mass Spectrometry: ASTM D7439-08.," 2008.

[11] AOAC International, "Lead,Cadmium, Zinc, Copper, and Iron in Foods Atomic Absorption Spectrophotometry after Microwave Digestion: AOAC Method 999.10," 2002.

[12] F. I. Abdulrahman, J. C. Akan, Z. M. Chellube, and M. Waziri, "Levels of heavy metals in human hair and nail samples from Maiduguri Metropolis, Borno State, Nigeria," World Environment, vol. 2, no. 4, pp. 81-89, 2012.

[13] K. Sriram, G. X. Lin, A. M. Jefferson, J. R. Roberts, R. N. Andrews, M. L. Kashon, and J. M. Antonini, "Manganese accumulation in nail clippings as a biomarker of welding fume exposure and neurotoxicity," Toxicology, vol. 291, no. 1-3, pp. 73-82, 2012. 


\section{AUTHOR PROFILE}

Azian Hariri is a senior lecturer and Head of Industrial and Indoor Environment Research Group (IIERG), Centre for Energy and Industrial Environment Studies (CEIES), Uni. Tun Hussein Onn, Malaysia 86400, Johor Malaysia (Phone:+607-4537880, Faks: +607-4536080, e-mail: azian@ uthm.edu.my).

Noraishah Mohamad Noor is a lecturer and committee of Research and Development Division with the DRB Hicom University of Automotive Malaysia, 26607, Pahang Malaysia (e-mail: noraishah@icam.edu.my).

N. Azreen Paiman is a PhD candidate under the Industrial and Indoor Environment Research Group, Centre for Energy and Industrial Environment Studies (CEIES), Uni. Tun Hussein Onn, Malaysia 86400, Johor Malaysia (e-mail: nuurazreenpaiman@yahoo.com.my). 